\title{
Rumen-protected methionine compared with rumen-protected choline improves immunometabolic status in dairy cows during the peripartal period
}

\author{
Z. Zhou, ${ }^{\star}$ O. Bulgari, ${ }^{\dagger} \dagger$ M. Vailati-Riboni, ${ }^{*}$ E. Trevisi,‡ M. A. Ballou,§ F. C. Cardoso, ${ }^{*}$ D. N. Luchini,\# \\ and J. J. Loor*1 \\ *Mammalian NutriPhysioGenomics, Department of Animal Sciences and Division of Nutritional Sciences, University of Illinois, Urbana 61801 \\ †Dipartimento di Medicina Molecolare e Traslazionale, Università degli Studi di Brescia, 25121 Brescia, Italy \\ łlstituto di Zootecnica Facoltà di Scienze Agrarie, Alimentari e Ambientali, Università Cattolica del Sacro Cuore, 29122, Piacenza, Italy \\ §Department of Animal Sciences, Texas Tech University, Lubbock 79409 \\ \#Adisseo, Alpharetta, GA 30022
}

\section{ABSTRACT}

The immunometabolic status of peripartal cows is altered due to changes in liver function, inflammation, and oxidative stress. Nutritional management during this physiological state can affect the biological components of immunometabolism. The objectives of this study were to measure concentrations of biomarkers in plasma, liver tissue, and milk, and also polymorphonuclear leukocyte function to assess the immunometabolic status of cows supplemented with rumen-protected methionine (Met) or choline (CHOL). Forty-eight multiparous Holstein cows were used in a randomized complete block design with $2 \times 2$ factorial arrangement of Met (Smartamine M, Adisseo NA, Alpharetta, GA) and CHOL (ReaShure, Balchem Inc., New Hampton, NY) level (with or without). Treatments (12 cows each) were control (CON), no Met or CHOL; CON and Met (SMA); CON and CHOL (REA); and CON and Met and CHOL (MIX). From -50 to $-21 \mathrm{~d}$ before expected calving, all cows received the same diet $[1.40 \mathrm{Mcal}$ of net energy for lactation $\left(\mathrm{NE}_{\mathrm{L}}\right) / \mathrm{kg}$ of $\left.\mathrm{DM}\right]$ with no Met or CHOL. From $-21 \mathrm{~d}$ to calving, cows received the same close-up diet $\left(1.52 \mathrm{Mcal}\right.$ of $\mathrm{NE}_{\mathrm{L}} / \mathrm{kg}$ of $\left.\mathrm{DM}\right)$ and were assigned randomly to each treatment. From calving to $30 \mathrm{~d}$, cows were on the same postpartal diet (1.71 Mcal of $\mathrm{NE}_{\mathrm{L}} / \mathrm{kg}$ of $\mathrm{DM}$ ) and continued to receive the same treatments until $30 \mathrm{~d}$. The Met supplementation was adjusted daily at $0.08 \% \mathrm{DM}$ of diet, and CHOL was supplemented at $60 \mathrm{~g} / \mathrm{cow}$ per day. Liver $(-10,7$, 21 , and $30 \mathrm{~d})$ and blood $(-10,4,8,20$, and $30 \mathrm{~d})$ samples were harvested for biomarker analyses. Neutrophil and monocyte phagocytosis and oxidative burst were assessed at d 1, 4, 14, and $28 \mathrm{~d}$. The Met-supplemented

Received February 3, 2016.

Accepted July 15, 2016.

${ }^{1}$ Corresponding author: jloor@illinois.edu cows tended to have greater plasma paraoxonase. Greater plasma albumin and IL-6 as well as a tendency for lower haptoglobin were detected in Met- but not CHOL-supplemented cows. Similarly, cows fed Met compared with CHOL had greater concentrations of total and reduced glutathione (a potent intracellular antioxidant) in liver tissue. Upon a pathogen challenge in vitro, blood polymorphonuclear leukocyte phagocytosis capacity and oxidative burst activity were greater in Met-supplemented cows. Overall, liver and blood biomarker analyses revealed favorable changes in liver function, inflammation status, and immune response in Met-supplemented cows.

Key words: inflammation, oxidative stress, transition cow, nutrition

\section{INTRODUCTION}

During the peripartal period, dairy cattle experience a state of negative energy and MP balance due to reduced DMI and increased nutrient requirements to support fetal growth and lactation (Drackley, 1999; Bell et al., 2000). Although some cows are able to adapt physiologically without being afflicted with metabolic and infectious diseases, the metabolic and immunologic challenges that occur during the peripartal period are important factors that limit the ability of most cows to achieve optimal performance and immunometabolic status (Drackley, 1999; Loor et al., 2013).

Due to extensive microbial degradation in the rumen, dietary availability of key methyl donors [(e.g., methionine (Met) and choline (CHOL)] are limited (Sharma and Erdman, 1989; Girard and Matte, 2005). Therefore, a negative methyl donor balance also may be an important challenge for the peripartal dairy cow owing to the fact that the synthesis of key compounds such as phosphatidylcholine (PC) and carnitine in tissues requires methyl donors (Pinotti et al., 2002). The biological role of methyl donors goes beyond metabolism because they are important sources of the intracellular 
antioxidants glutathione (GSH) and taurine (Brosnan and Brosnan, 2006).

In the context of liver metabolism and function, endogenous synthesis of PC from supplemental Met or CHOL could play a role in the ability of the tissue to handle the incoming fatty acids produced from lipolysis of adipose tissue. It is well established that excessive hepatic fatty acid infiltration (Drackley, 1999) can negatively affect the normal functions of the liver. In addition to hepatic fat infiltration, the peripartal period is characterized by an increase of reactive oxygen metabolite (ROM) production, the accumulation of which could deplete intracellular antioxidants such as GSH and give rise to oxidative stress that may cause substantial tissue damage (Bertoni et al., 2009; Sordillo et al., 2009; Trevisi et al., 2012). Increased oxidative stress likely leads to inflammation and could compromise the leukocyte responses during the peripartal period.

Biomarkers in plasma, such as cholesterol and paraoxonase (PON), among others, have been used successfully to assess the degree of liver function around parturition (Bionaz et al., 2007; Bertoni et al., 2008; Loor et al., 2013). Furthermore, because parturition also is characterized by inflammatory conditions (Bionaz et al., 2007), proinflammatory cytokines (e.g., IL-1 $\beta$; Trevisi et al., 2015) and the changes in concentrations of positive (e.g., haptoglobin) and negative acute-phase proteins (APP) offer a valuable tool to evaluate the functional welfare of the cow (Loor et al., 2013). Changes in inflammatory cytokines are closely linked with PMNL development and immunity-related activities (Burton et al., 2005); thus, coupling plasma biomarkers with measures of leukocyte function provide a more holistic view of the cow immune system. Immune dysfunction is a feature of the transition period and is characterized by impaired neutrophil trafficking, phagocytosis, and killing capacity (Kehrli et al., 1989; Goff and Horst, 1997), but also different ability of leukocytes to produce cytokines (Jahan et al., 2015). In the context of transition period management, the available data provide benchmarks that could be used to assess relationships among liver function, performance, and fertility (Bertoni and Trevisi, 2013).

Milk from dairy cows is high in methylated compounds and the levels secreted into milk are maintained even at the cost of depleting liver tissue reserves $(\mathrm{Pi}-$ notti et al., 2002). Such an effect would exert an even greater challenge on the cow soon after calving, and coupled with the needs of cells to synthesize sulfurcontaining antioxidants the supplementation of Met (and potentially CHOL) may be beneficial. However, to date, data demonstrating whether $\mathrm{CHOL}$ alone or in combination with Met provide equal or different benefits to the immunometabolic status in transition cows are limited.

Our general hypothesis was that supplementation of rumen-protected Met or CHOL improves liver function and alleviates inflammation and oxidative stress during the peripartal period. Therefore, the objectives of the present study were to measure concentrations of biomarkers in plasma, liver tissue, and milk, as well as PMNL function to assess the immunometabolic status of cows supplemented with Met or CHOL.

\section{MATERIALS AND METHODS}

\section{Experimental Design and Dietary Treatments}

All procedures for this study (protocol no. 13023) were approved by the Institutional Animal Care and Use Committee of the University of Illinois. Details of the experimental design have been described previously (Zhou et al., 2016b). Briefly, the experiment was conducted as a randomized complete block design with $2 \times 2$ factorial arrangement of Met (Smartamine M, Adisseo NA, Alpharetta, GA) and CHOL (ReaShure, Balchem Inc., New Hampton, NY) level (with or without). Cows were blocked according to expected calving date. Each block had 12 cows (except for the last block). Cows within each block were balanced for parity, previous lactation milk yield, and BCS before the close-up treatments were assigned. A total of 81 cows were used in a randomized, complete, unbalanced block design with $2 \times 2$ factorial arrangement of Met and CHOL level (with or without). Treatments were control $(\mathbf{C O N}, \mathrm{n}=20)$, with no Met or CHOL supplementation; Smartamine (SMA, $\mathrm{n}=21$ ), CON plus Met at a rate of $0.08 \%$ of DM; Reashure $(\mathbf{R E A}, \mathrm{n}=20)$, CON plus CHOL at $60 \mathrm{~g} / \mathrm{d}$; or Smartamine and Reashure (MIX, n $=20$ ), CON plus Met plus CHOL. Dosage of Met was based on Osorio et al. (2013), whereas CHOL was supplemented following the manufacturer's recommendations. Per Institutional Animal Care and Use Committee guidelines, a subset of 48 multiparous cows (12 cows/treatment) were used for this portion of the study. All cows received the same far-off diet (1.40 Mcal $/ \mathrm{kg}$ of DM, $10.2 \% \mathrm{RDP}$, and $4.1 \%$ RUP) from -50 to -22 d before expected calving, close-up $\operatorname{diet}(1.52 \mathrm{Mcal} / \mathrm{kg}$ of DM, 9.1\% RDP, and $5.4 \%$ RUP) from $-21 \mathrm{~d}$ to expected calving, and lactation diet from calving (1.71 Mcal $/ \mathrm{kg}$ of DM, 9.7\% RDP, and $7.5 \%$ RUP) through 30 DIM.

The Met and CHOL supplements were both topdressed from $-21 \pm 2$ to 30 DIM once daily at the morning feeding using approximately $50 \mathrm{~g}$ of ground 
corn as carrier for all treatments. Supplementation of SMA $(0.08 \%$ DM of TMR offered) was calculated daily for each cow. Smartamine M was supplied as small beads containing a minimum of $75 \%$ DL-Met, physically protected by a $\mathrm{pH}$-sensitive coating, which is considered to have a Met bioavailability of $80 \%$ (Graulet et al., 2005); therefore, per $10 \mathrm{~g}$ of SMA, the cows received $6 \mathrm{~g}$ of metabolizable Met. The REA supplement is reported to contain $28.8 \%$ choline chloride and is protected by microencapsulation. The product is considered to have CHOL bioavailability of $72 \%$ (Benoit, 2009); therefore, per $60 \mathrm{~g}$ of REA, the cows received $12.4 \mathrm{~g}$ of metabolizable choline chloride. To our knowledge, neither SMA nor REA have specific characteristics that may affect palatability of diets.

\section{Animal Management}

Dry cows were housed in a ventilated enclosed barn during the dry period and fed individually once daily at $0630 \mathrm{~h}$ using an individual gate system (American Calan Inc., Northwood, NH). Cows had access to sandbedded freestalls until 3 d before expected parturition, when they were moved to individual maternity pens bedded with straw until parturition. On average, cows remained in the maternity pen for $3.69 \pm 3.61 \mathrm{~d}$. After parturition, cows were housed in a tiestall barn and were fed a common lactation diet once daily and milked $3 \times$ daily at approximately 0600, 1400, and 2200 through the end of the trial at 30 DIM. Feed offered was adjusted daily to achieve $\sim 10 \%$ refusals.

\section{Blood, Milk, and Liver Sample Collection and Biomarker Analyses}

Blood was sampled for biomarker analysis from the coccygeal vein on $\mathrm{d}-10$ relative to expected calving date and on $\mathrm{d} 4,8,20$, and 30 relative to actual calving date before the morning feeding. An additional tube of plasma was collected on $\mathrm{d} 1,4,14$, and 28 relative to calving for neutrophil and monocyte phagocytosis and oxidative burst analyses. Samples were collected into evacuated tubes (BD Vacutainer; BD and Co., Franklin Lakes, NJ) containing either clot activator or lithium heparin for serum and plasma, respectively.

Consecutive morning, midday, and evening milk samples were collected every Wednesday and Saturday until 30 DIM (Zhou et al., 2016b). Weekly composite milk samples were prepared in proportion to milk yield at each milking and frozen at $-20^{\circ} \mathrm{C}$ until analysis.

Liver was sampled via puncture biopsy (Dann et al., 2005) from cows under local anesthesia at approximate- ly $0800 \mathrm{~h}$ on $\mathrm{d}-10,7,20$, and $30 \mathrm{~d}$ relative to parturition. Liver was frozen immediately in liquid nitrogen and stored until analysis.

Serum or plasma was analyzed for creatinine, urea, bilirubin, aspartate aminotransferase, gamma-glutamyl transferase, cholesterol, PON, albumin, ceruloplasmin, haptoglobin, myeloperoxidase (MPO), ROM, and ferric-reducing ability of plasma using kits purchased from Instrumentation Laboratory (Lexington, MA) following the procedures described previously (Jacometo et al., 2015) using the clinical auto-analyzer (ILAB 600, Instrumentation Laboratory). Bovine IL-1 $\beta$ (Cat. No. ESS0027; Thermo Scientific, Rockford, IL) and IL-6 (Cat. No. ESS0029; Thermo Scientific) plasma concentration were determined using commercial kits. Plasma phosphatidylcholine (Cat. No.10009926; Cayman Chemical, Ann Arbor, MI) and free CHOL (Cat. No. K615-100; Biovision Inc., Milpitas, CA) concentration were quantified using commercial kits. The concentration of free CHOL in milk was determined in weekly composite samples (Cat. No. KA1662; Abnova, Taipei City, Taiwan).

The simultaneous phagocytosis capacity and oxidative burst activity of peripheral monocytes and neutrophils was determined upon challenge with enteropathogenic bacteria (Escherichia coli 0118:H8) as described by Hulbert et al. (2011) with modifications. Briefly, 200 $\mu \mathrm{L}$ of whole blood with $40 \mu \mathrm{L}$ of $100 \mu M$ dihydrorhodamine 123 (Sigma-Aldrich, St. Louis, MO), and 40 $\mu \mathrm{L}$ of propidium iodine-labeled bacteria $\left(10^{9} \mathrm{cfu} / \mathrm{mL}\right)$ were incubated at $38.5^{\circ} \mathrm{C}$ for $10 \mathrm{~min}$. After red blood cells were lysed with ice-cold distilled deionized water, cells were resuspended in PBS solution. Subsequently, monocytes were marked with allophycocyanin-labeled anti-CD14 antibody (Cat. No. 301808; Biolegend, San Diego, CA) whereas neutrophils were stained with CH138A primary anti-bovine granulocyte monoclonal antibody (Cat. No. BOV2067, Washington State University, Pullman) and phycoerythrin-labeled secondary antibody (Cat. No. 1020-09S, Southern Biotech, Birmingham, AL). Lastly, the cells were resuspended in PBS solution for flow cytometry analyses (LSR II; Becton Dickinson, San Jose, CA). Neutrophils and monocytes were gated based on their side scatter properties in combination with the phycoerythrin and allophycocyanin signal, respectively. Compared with the negative controls, the neutrophils and monocytes from E. coli-stimulated samples with greater emissions of propidium iodine were considered positive for phagocytosis. Similarly, compared with negative controls the E. coli-stimulated samples with greater emissions of rhodamine 123 were considered positive for oxidative burst. Data are reported as percentages of CD14- and 
CH138A-positive cells with phagocytosis and oxidative burst capability. The detailed protocol of the assay is described in the supplemental materials (http://dx.doi. org/10.3168/jds.2016-10986).

Liver tissue total and oxidized GSH were measured at $-10,7,20$, and $30 \mathrm{~d}$ relative to parturition using a commercial kit (Cat. No. NWH-GSH01; Northwest Life Science Specialties LLC, Vancouver, WA). Reduced GSH was calculated as reduced GSH $=$ total GSH oxidized GSH.

\section{Statistical Analysis}

Data were analyzed using PROC MIXED of SAS (SAS Institute Inc., Cary, NC) according to the following model:

$$
\begin{aligned}
y_{i j k l m}= & \mu+b_{i}+M_{j}+C_{k}+M C_{j k}+T_{l}+T M_{j l} \\
& +T C_{k l}+T M C_{j k l}+A_{m: i j k}+\varepsilon_{i j k l m},
\end{aligned}
$$

where $y_{i j k l m}$ is the dependent, continuous variable; $\mu$ is the overall mean; $b_{i}$ is the random effect of the $i$ th block; $M_{j}$ is the fixed effect of Met $(j=$ with or without); $C_{k}$ is the fixed effect of CHOL ( $k=$ with or without); $T_{l}$ is the fixed effect of time (day or week) of the experiment; $A_{m: i j k}$ is the random effect of the $m$ th animal (cow) nested within block $\times$ Met $\times$ CHOL; and $\varepsilon_{i j k l m}$ is the residual error. The covariate for parity (second vs. third lactation and above) was maintained in the model for all variables when significant $(P<0.05)$. Blood metabolites and liver composition were analyzed at various time points that were not equally spaced. Therefore, an exponential correlation covariance structure SP (POW) was used for repeated measures. Least squares means separation between time points was performed using the PDIFF statement. Statistical differences were declared significant at $P \leq 0.05$ and tendencies at $P \leq 0.10$.

\section{RESULTS}

\section{Biomarkers of Muscle Mass Catabolism and $\mathbf{N}$ Metabolism}

Main effects of Met, CHOL, time, and interactions are presented in Table 1. As expected, creatinine concentrations in all treatments gradually decreased after calving (Supplemental Figure S1; http://dx.doi.org/10.3168/ jds.2016-10986). A lower creatinine concentration in plasma was detected due to the main effect of $\mathrm{CHOL}$ $(P=0.02$, Supplemental Figure S1B $)$ but not Met $(P$ $>0.05$, Supplemental Figure S1A). Unlike creatinine, overall concentration of urea in plasma did not differ in response to Met or CHOL, and was only affected by time $(P<0.01)$ because of an increase after calving.

\section{Biomarkers of Liver Function}

Main effects of Met, CHOL, time, and interactions for liver function biomarkers are summarized in Table 1. Neither Met nor CHOL supplementation had an effect on cholesterol concentrations or aspartate aminotransferase $(P>0.10$, Table 1$)$. However, a tendency $(P=$ $0.07)$ was detected in cows fed Met due to an overall greater increase in PON concentrations compared with cows without Met supplementation, especially after calving. Although concentration of PON in cows fed CHOL also increased $(P<0.01)$ over time after calving, CHOL did not result in greater PON compared with cows without CHOL supplementation $(P=0.87$, Figure 1D).

\section{Biomarkers of CHOL Metabolism}

The main effect of Met, CHOL, and their interactions for blood and milk CHOL metabolism biomarkers are reported in Table 1. The main effects of Met and CHOL and their interactions were not significant $(P>0.05)$ for any of the CHOL metabolism biomarkers (Table 1). Regardless of treatment, plasma $\mathrm{PC}$ and free $\mathrm{CHOL}$ concentrations decreased $(P<0.05)$ around calving and reached a nadir at $4 \mathrm{~d}$ after parturition. Unlike PC, plasma free CHOL concentration remained low after 4 $\mathrm{d}$ and did not return to prepartum levels by 30 DIM (Supplemental Figure S2; http://dx.doi.org/10.3168/ jds.2016-10986), which could be mainly attributed to the constant increase in milk CHOL regardless of treatment $(P<0.01$, Supplemental Figure S2).

\section{Biomarkers of Inflammation and APP}

Among the APP determined in the present study, Met-supplemented cows had greater albumin concentration $(P=0.04)$ compared with cows without Met. In fact, plasma albumin in Met cows increased $(P<0.05$, Figure $2 \mathrm{C}$ ) after calving, whereas albumin concentration in cows without Met supplementation remained unchanged compared with the prepartum period $(P>$ 0.05). As expected, plasma haptoglobin concentration increased $(P<0.01$, Figure $2 \mathrm{~A}$ and $2 \mathrm{~B})$ soon after calving. Although plasma haptoglobin reached a zenith on d 4 regardless of treatment, a tendency $(P=0.08)$ for lower haptoglobin was detected in response to Met supplementation but not CHOL $(P=0.94)$. 
ZHOU ET AL.

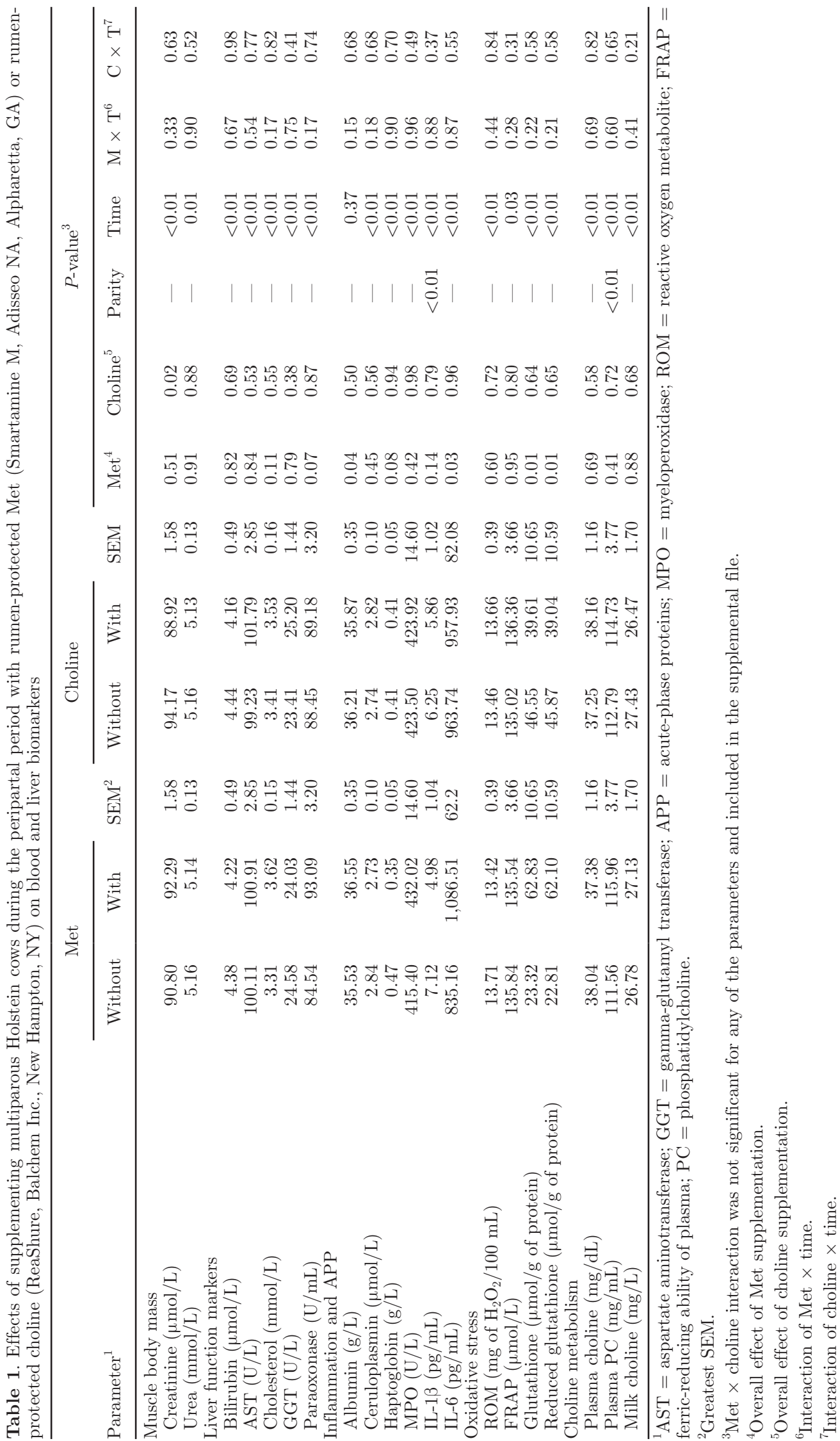




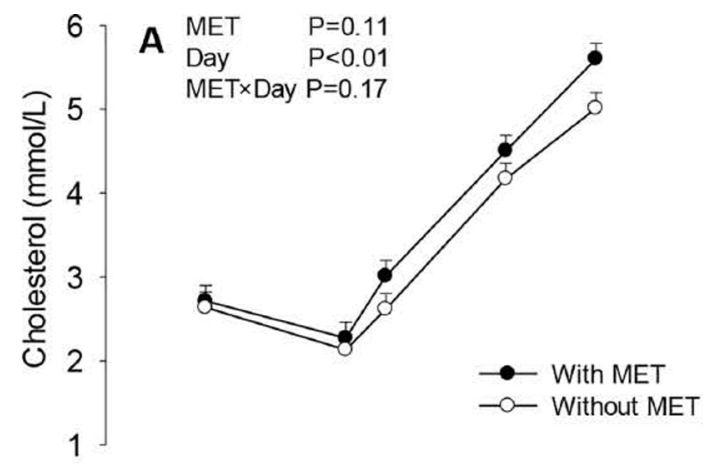

For proinflammatory cytokines, we observed no main effect or interactions for CHOL. In contrast, a main effect with greater IL-6 in Met-supplemented cows was detected $(P=0.03$, Figure $3 \mathrm{G})$; IL-1 $\beta$ concentration did not change $(P=0.14$, Figure $2 \mathrm{E})$ in Met-supplemented cows.

\section{Biomarkers of Oxidative Stress}

Although no main effect or interactions of Met and CHOL were detected for plasma MPO, ROM, or ferricreducing ability of plasma, the concentration of ROM increased after calving and did not return to prepartum level by 30 DIM regardless of treatment (data not shown). In accordance with the temporal changes in ROM, liver total and reduced GSH concentrations decreased after calving and did not return to prepartum level by 30 DIM. However, unlike ROM, liver total ( $P$ $=0.01$, Figure $3 \mathrm{~A})$ and reduced GSH $(P=0.01$, Figure $3 \mathrm{C}$ ) were greater in Met-supplemented cows, which was mainly attributed to greater concentration of total and reduced GSH on d -10 and 30 relative to parturition.

\section{Whole-Blood Phagocytosis and Oxidative Burst}

Upon challenge, a greater increase in neutrophil phagocytosis capability was detected in cows supplemented with Met $(P=0.01$, Figure $4 \mathrm{~A})$ but not CHOL $(P=0.81$, Figure 4B). In contrast, for blood monocytes, phagocytosis capability did not change in response to Met $(P=0.28$, Supplemental Figure S3A; http://dx.doi.org/10.3168/jds.2016-10986) or CHOL $(P=0.15$, Supplemental Figure S3B).

As expected, Met supplementation also resulted in greater blood neutrophil oxidative burst $(P=0.03$, Figure $4 \mathrm{C})$. In contrast, blood neutrophil oxidative burst did not change in response to CHOL supplementation $(P=0.54$, Figure $4 \mathrm{D})$. Although differences in monocyte oxidative burst capability were not detected for the main effects of Met or CHOL $(P>0.10)$, a significant Met $\times$ CHOL interaction $(P<0.01$, Table 2 ) occurred mainly due to increased monocyte oxidative burst capability in SMA- and REA-supplemented cows. No temporal changes were detected for blood monocyte $(P=0.77$, Supplemental Figure S3; http:// dx.doi.org/10.3168/jds.2016-10986) and neutrophil $(P$ $=0.45$, Figure 4) oxidative burst activity.

\section{DISCUSSION}

during the peripartal period with rumen-protected methionine (Met Smartamine M, Adisseo NA, Alpharetta, GA) or rumen-protected choline (CHOL; ReaShure, Balchem Inc., New Hampton, NY) on blood cholesterol (A, B) and paraoxonase (C, D). Values are means, with standard errors represented by vertical bars; Met $\times$ CHOL interactions were not significant $(P>0.05)$ for any of the parameters, and thus only Met and CHOL main effects are plotted.

\section{Biomarkers of Muscle Mass and N Metabolism}

During the periparturient period, the inability of cows to consume sufficient protein leads to negative 

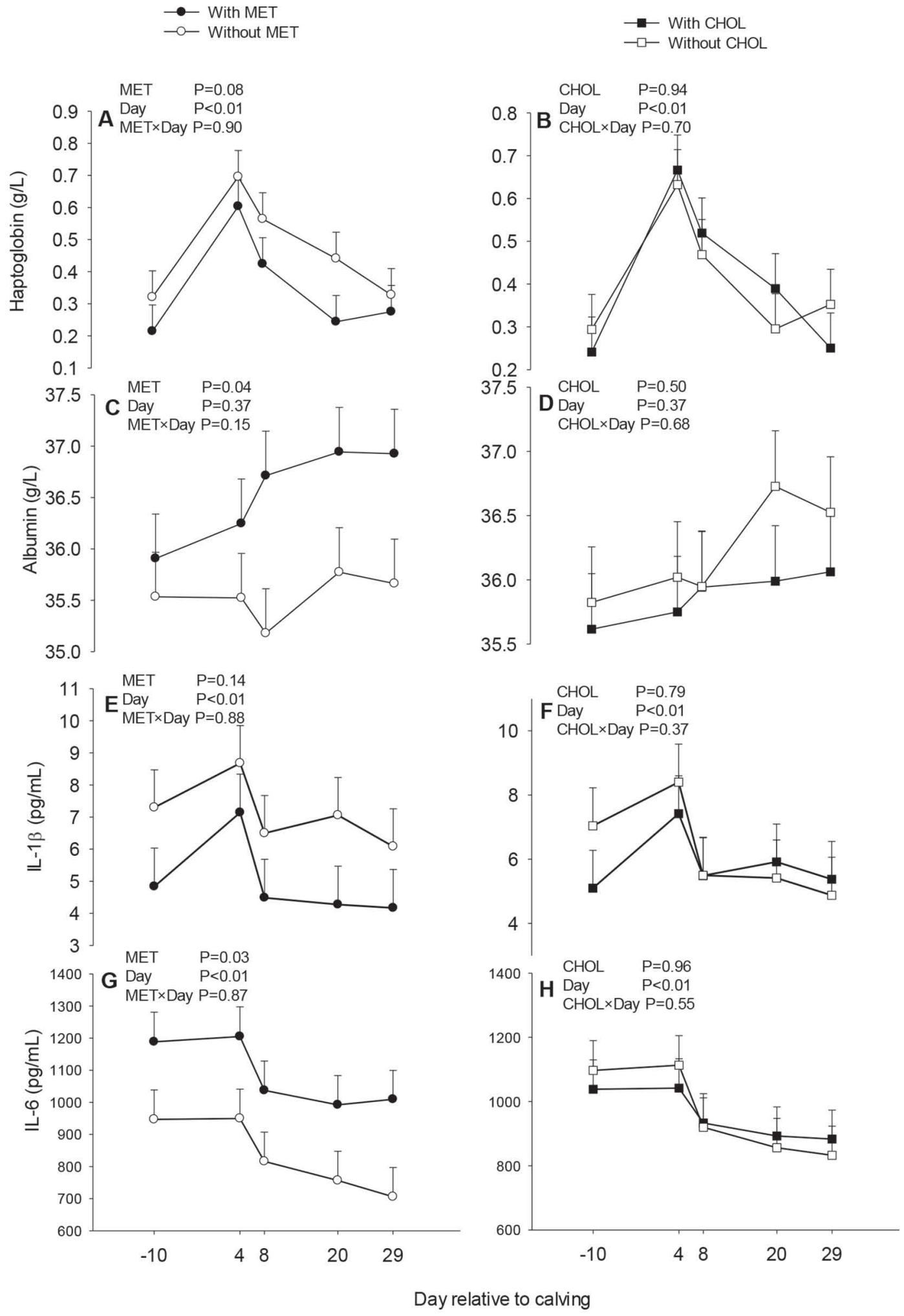

Figure 2. Effects of supplementing multiparous Holstein cows during the peripartal period with rumen-protected methionine (Met; Smartamine M, Adisseo NA, Alpharetta, GA) or rumen-protected choline (CHOL, ReaShure, Balchem Inc., New Hampton, NY) on blood haptoglobin (A, B), albumin (C, D), IL-1 $(\mathrm{E}, \mathrm{F})$, and IL-6 (G, H). Values are means, with standard errors represented by vertical bars; Met $\times$ CHOL interactions were not significant $(P>0.05)$ for any of the parameters, and thus only Met and CHOL main effects are plotted. 

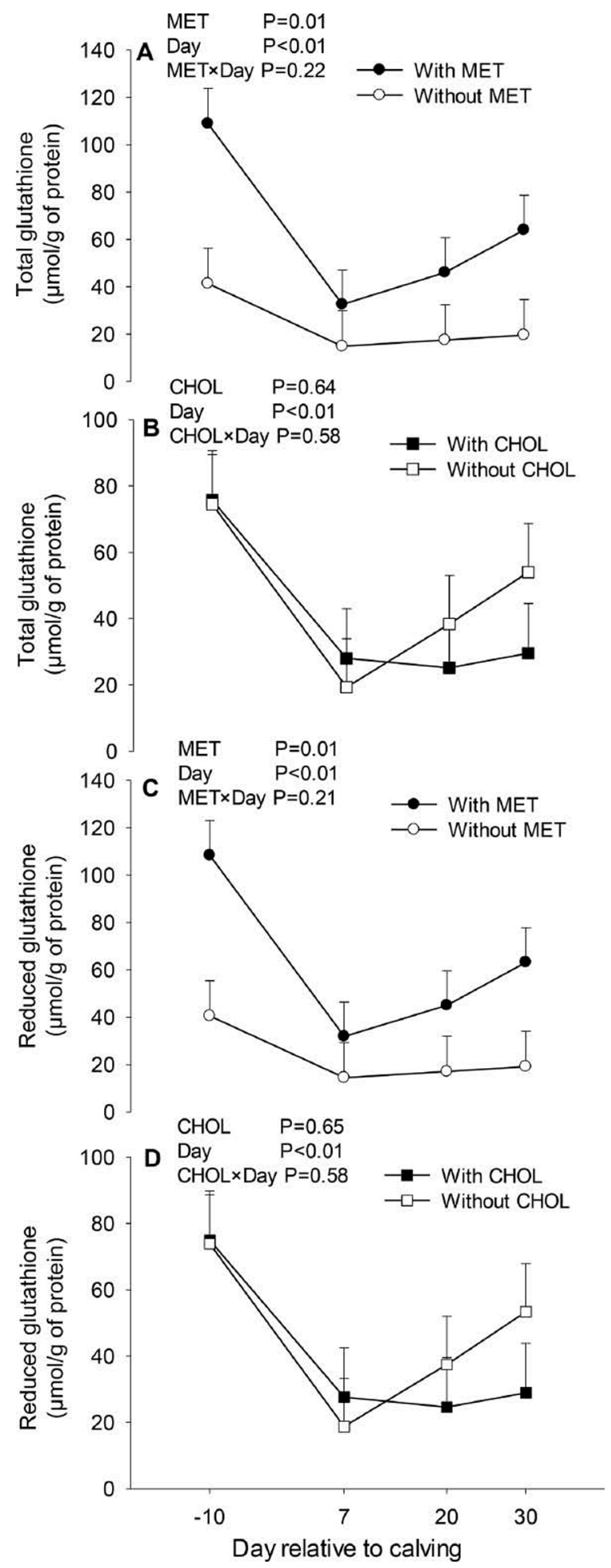

Figure 3. Effects of supplementing multiparous Holstein cows during the peripartal period with rumen-protected methionine (Met; Smartamine M, Adisseo NA, Alpharetta, GA) or rumen-protected choline (CHOL, ReaShure, Balchem Inc., New Hampton, NY) on liver total glutathione (A, B) and reduced glutathione $(\mathrm{C}, \mathrm{D})$. Values are means, with standard errors represented by vertical bars; Met $\times$ CHOL interactions were not significant $(P>0.05)$ for any of the parameters, and thus only Met and CHOL main effects are plotted.
MP balance and lower plasma AA, especially around parturition (Bell et al., 2000; Zhou et al., 2016a). Considering that the demands for fetal development in late pregnancy and the onset of lactation greatly increase the tissue requirements for $\mathrm{AA}$, muscle mobilization during this period can be expected. Creatinine is a suitable indicator of body muscle mass, and the plasma level of creatinine has been used as an indirect marker for evaluation of body muscle catabolism both in the peripartal period (Kokkonen et al., 2005; Osorio et al., 2014) and mid lactation (Pires et al., 2013). Thus, the lower plasma concentration of creatinine in CHOL cows indicated less body mass in these cows and, therefore, a higher degree of muscle mass mobilization. The mechanism for such response is unclear; however, it is likely to be associated with reduced insulin sensitivity in these cows because blood glucose-to-insulin ratio was lower in response to CHOL supplementation during the peripartal period (Zhou et al., 2016b).

\section{Biomarkers of Liver Function and Choline Metabolism}

It is well known that cholesterol is required for synthesis of the hydrophobic core of lipoproteins synthesized in liver or the intestine (Cohen, 2008), and the concentrations of the various lipoprotein fractions are modified greatly around parturition (Bionaz et al., 2007). The suitability of cholesterol as a biomarker of liver function during the peripartal period is partly because the variation in concentrations depends to a large extent on the lipoprotein level in blood (Bionaz et al., 2007).

As lipotropic agents, Met and CHOL fed to ruminants may help clear lipid from the liver through stimulating very low density lipoprotein formation and export (Waterman and Schultz, 1972). Previous reports from both nonruminant and ruminant studies have illustrated the importance of adequate lipotropic agents in the prevention of hepatic lipidosis (Cooke et al., 2007; Corbin and Zeisel, 2012).

As precursor of $\mathrm{PC}$, which is essential for very low density lipoprotein synthesis (Auboiron et al., 1995), CHOL supplementation also was expected to improve liver function at least in part by enhancing lipoprotein export from liver. In contrast with this notion, results from previous reports either observed no differences (Guretzky et al., 2006) or detected a lower concentration (Zahra et al., 2006) of blood cholesterol in response to CHOL supplementation. Thus, the lack of change in plasma cholesterol in CHOL-supplemented cows is not entirely surprising (Table 1). In agreement with these results, the fact that plasma $\mathrm{PC}$ concentration also was not affected by CHOL supplementation, together with 


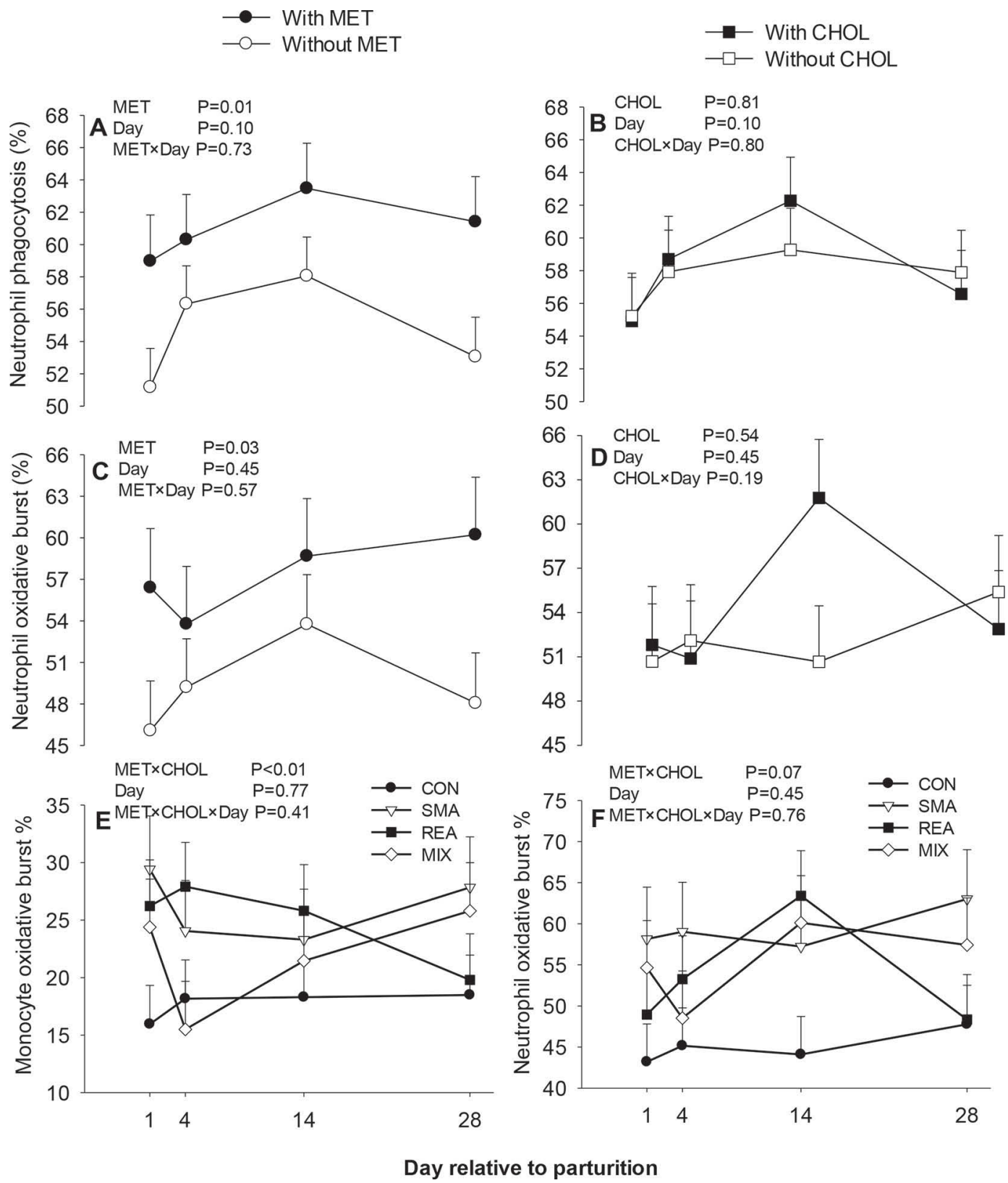

Figure 4. Effects of supplementing multiparous Holstein cows during the peripartal period with rumen-protected methionine (Met; Smartamine M, Adisseo NA, Alpharetta, GA) or rumen-protected choline (CHOL; ReaShure, Balchem Inc., New Hampton, NY) on phagocytosis (A, B) and oxidative burst (C, D, E, F). CON = control; SMA = Smartamine M (0.08\% of DMI); REA = ReaShure $(60 \mathrm{~g} / \mathrm{d})$; MIX = SMA+REA. Values are means, with standard errors represented by vertical bars.

the higher liver triacylglycerol on $20 \mathrm{~d}$ in the CHOLsupplemented cows (Zhou et al., 2016b), indicated that the export of lipoproteins from liver was not increased.

Paraoxonase is synthesized in the liver, after which it is released into the blood stream where it associates with high-density lipoprotein and protects it from oxidative damage (Turk et al., 2004). Therefore, PON concentration has been used as one biomarker of liver function in peripartal cows (Bionaz et al., 2007). In fact, cows with high concentrations of PON in plasma (average $=92 \mathrm{U} / \mathrm{mL}$ ) postpartum produced more milk compared with those with low PON concentrations (average $=54.3 \mathrm{U} / \mathrm{mL}$ ) (Bionaz et al., 2007). Although of a lower magnitude, the difference in PON detected between cows with or without Met supplementation (94.9 vs. $85.1 \mathrm{U} / \mathrm{mL}$ ) seems to support the idea they were in better health and, hence, produced more milk (Zhou et al., 2016b). 


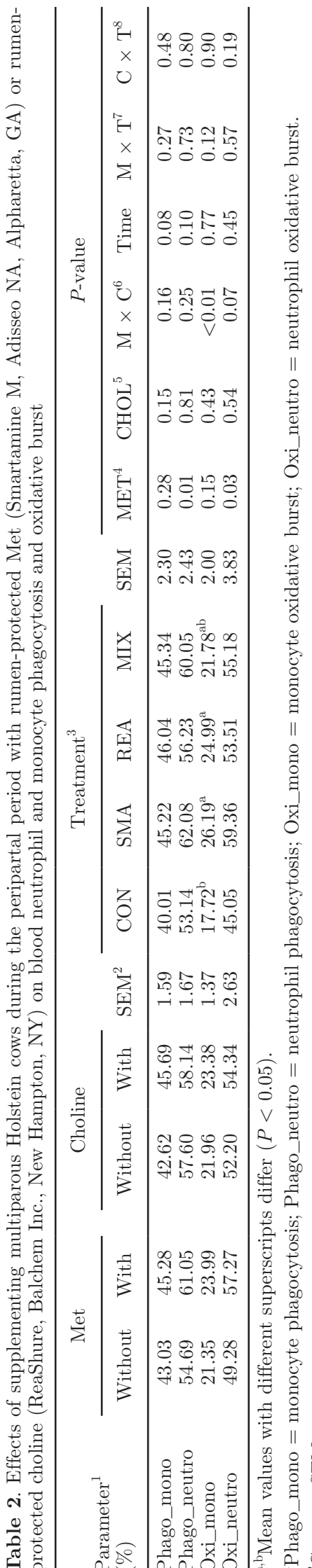

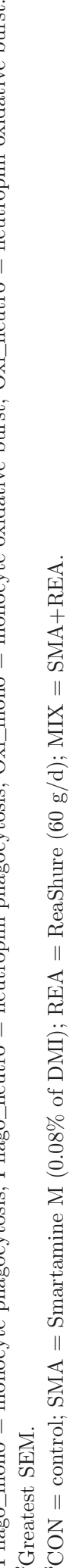

The general trend of decrease in PON around parturition with a nadir at $4 \mathrm{~d}$ postpartum (Figure 1C) was in agreement with previous work (Bionaz et al., 2007; Grossi et al., 2013; Osorio et al., 2014). It was proposed previously that excessive deposition of triacylglycerol in liver and its negative effect on hepatocytes was partly responsible for the decrease in PON after calving (Turk et al., 2004). However, the fact that liver triacylglycerol increased after calving (Zhou et al., 2016b) regardless of treatment does not seem to support a negative effect on PON. What is apparent from the present study and data on high-density lipoprotein profiles after calving (Bernabucci et al., 2004) is that PON plays a role in lipoprotein metabolism besides potentially alleviating negative effects of oxidative stress (Aviram and Rosenblat, 2004). In that context, it is noteworthy that the overall correlation between PON and cholesterol was positive regardless of treatment (240 observations total; $\mathrm{r}=0.50, P<0.01)$.

\section{Biomarkers of Inflammation and APP}

As a negative APP, hepatic production of albumin is commonly decreased during inflammation and serves as a useful biomarker to evaluate the inflammatory status of cows (Bionaz et al., 2007; Bertoni et al., 2008; Ceciliani et al., 2012). For instance, cows experiencing fewer (or none) cases of milk fever, retained placenta, metritis, ketosis, lameness, or mastitis during the first month of lactation and producing higher levels of milk (Bertoni et al., 2008) than those cows experiencing one or more of these health complications had albumin concentrations ranging between $\sim 34$ and $\sim 35 \mathrm{~g} / \mathrm{L}$ at 7 through 28 d postpartum [(Table 2 in Bionaz et al. (2007); Figure 1 in Bertoni et al., (2008)] and levels of haptoglobin $>0.3$ $\mathrm{g} / \mathrm{L}$ (suggestive of serious inflammation; Bertoni et al., 2008; Bionaz et al., 2007). Therefore, although plasma albumin concentrations in cows with or without Met or CHOL were above $35 \mathrm{~g} / \mathrm{L}$ throughout the peripartal period (Figure 2), the greater concentration of albumin $(1 \mathrm{~g} / \mathrm{L})$ in Met-supplemented cows could be taken as indication that they were in better health.

It also is noteworthy that cows without Met maintained a constant concentration of albumin throughout the study whereas the concentration in Met cows was already numerically greater at d 4 compared with -10 relative to parturition and continued to increase at 8 $\mathrm{d}$ postpartum. Considering the detoxification function of albumin upon binding to nonesterified fatty acids as well as bilirubin, the greater concentration of albumin in Met-supplemented cows may have helped alleviate inflammation (Weinberg, 2006; van der Vusse, 2009) during the peripartal period. It is also noteworthy that, in spite of an apparently greater hepatic synthesis of 
albumin in Met-supplemented cows, they also had greater overall milk protein percentage and milk yield (Zhou et al., 2016b). It has been suggested that a reduction in the synthesis of albumin within the liver would spare AA for gluconeogenesis and production of hepatic proteins, especially positive APP (Ceciliani et al., 2012).

Production of the positive APP, such as haptoglobin and ceruloplasmin, are expected to increase during an inflammatory event. In transition cow research, haptoglobin has been of particular interest due to its quick increase during the acute-phase response and has, therefore, been used as diagnostic biomarker previously (Hirvonen et al., 1999; Sheldon et al., 2001). In terms of the peripartal period, haptoglobin concentration in blood is commonly elevated as a consequence of common inflammatory conditions around calving (Bionaz et al., 2007); for example, stimulation of parenchymal cells by fatty acid infiltration of the liver in transition cows (Eckersall, 2000; Katoh et al., 2002). The overall positive correlation (240 observations total; $\mathrm{r}=0.14, P$ $=0.03$ ) between haptoglobin and IL-1 $\beta$ was indicative of a proinflammatory state during the transition period because evidence exists that IL-1 $\beta$ (proinflammatory cytokine) can stimulate transcription and synthesis of haptoglobin (Baumann et al., 1990). In accordance with the greater albumin in Met cows, the tendency for a lower concentration of blood haptoglobin offers some support for the idea that these cows were under a less pronounced inflammatory state.

Although IL-6 is well-known for its proinflammatory properties, recent findings have revealed an anti-inflammatory property for this cytokine (Scheller et al., 2011). In fact, the anti-inflammatory activities of IL-6 are mediated by gp130 and IL-6R (classic signaling), whereas proinflammatory activities are mediated by the IL-6-soluble IL-R complex (trans-signaling; Scheller et al., 2011). Therefore, depending on a given stimulus inducing a given signaling pathway, IL-6 should be considered as both a pro- and an anti-inflammatory cytokine. Because IL-6 does not upregulate major inflammatory mediators and directly inhibits TNFo and IL-1 expression and their signal transduction (Rehman et al., 1997), the current view is that IL-6 has primarily an anti-inflammatory effect (Pedersen et al., 2001; Lauder et al., 2013; Hunter and Jones, 2015). Therefore, considering the tendency for lower haptoglobin as well as the markedly greater albumin in Metsupplemented cows, it is reasonable to speculate that the higher IL-6 concentration in Met-supplemented cows reflected a less pronounced inflammatory status. It also is possible that the greater IL- 6 concentration in Met-supplemented cows served to maintain a cer- tain degree of peripheral tissue inflammation (VailatiRiboni et al., 2016).

\section{Biomarkers of Oxidative Stress}

Oxidative stress, defined as the serious imbalance between oxidants and antioxidants as a consequence of augmented ROM production due to the increased demand for nutrients and energy, can exert pleiotropic actions in peripartal dairy cows (Sordillo et al., 2009). In fact, ROM has been widely adopted as a biomarker for oxidative stress in both nonruminants (Fukui et al., 2011; Jansen et al., 2013) and ruminants (Bernabucci et al., 2002, 2005; Trevisi et al., 2009; Celi et al., 2010). Although ROM concentrations in the present study were not affected by Met or CHOL supplementation, the substantially higher ROM starting at $4 \mathrm{~d}$ postpartum was indicative of an increased risk for the onset of oxidative stress. In that context, it is noteworthy that cows supplemented with Met had clear signs of a reduced inflammatory status. The reason for this is unclear but it could have been related to the differences between groups in the concentration of intracellular antioxidants such as GSH. In fact, GSH is the most abundant endogenous antioxidant due to its marked ability to scavenge ROM and free radicals. Hence, concentration of GSH has been used as biomarker in various oxidative stress-related diseases (Romeu et al., 2010; Vetrani et al., 2013; Saharan and Mandal, 2014). The overall decrease in total and reduced GSH concentration after parturition could have been due to the increased production of ROM and free radicals.

Previous work with dairy cows has demonstrated a positive effect of Met supplementation on intrahepatic GSH concentration during the peripartal period (Osorio et al., 2014). Such an effect may be directly associated with Met supplementation, considering that Met can be incorporated upstream in the de novo synthesis pathway for GSH (Halsted, 2013). Studies with nonruminants have also observed reduced concentrations of hepatic GSH in cases of protein-energy malnutrition, with GSH being replenished when sulfur AA or methyl donors are supplemented (Cho et al., 1984; Bauman et al., 1988; Goss et al., 1994). In fact, both in vitro (Hartman et al., 2002) and in vivo (Tabachnick and Tarver, 1955) studies using radioactive-labeled methionine have demonstrated hepatic incorporation of $\left.{ }^{35} \mathrm{~S}\right]$ into GSH. Therefore, the higher GSH concentration in Met-supplemented cows was in agreement with these reports and confirm a direct association between Met supplementation and hepatic GSH concentration.

Although CHOL does not contain sulfur, Met can be generated in tissues such as the liver from CHOL when 
homocysteine accepts a methyl group from CHOL through betaine (Wong and Thompson, 1972; Li and Vance, 2008). Therefore, an increase in hepatic GSH also was expected from CHOL supplementation, but it did not occur (Figure 3). Because cysteine is the limiting substrate for GSH synthesis and receives sulfur from Met (Franklin et al., 2009), it is reasonable to speculate that lack of sulfur was a key limiting factor for GSH synthesis from CHOL supplementation. Alternatively, it also is possible that Met synthesis from CHOL was limited during the peripartal period, either as a result of insufficient expression or activity of key enzymes (e.g., betaine homocysteine methyltransferase), or because CHOL was predominantly used for synthesis of other compounds such as PC or acetylcholine. The specific mechanisms for this response merit further study.

\section{Blood Neutrophil and Monocyte Killing Capacity}

Compromised neutrophil and monocyte phagocytic capacity and oxidative burst activity in response to pathogen challenge are direct indicators of an impaired immune response, resulting in increased risk of bacterial infections to the host (Unanue, 1976). Data available to date seem to indicate that peripartal dairy cows have a dysfunctional immune system around calving (Loor et al., 2013). Therefore, the greater neutrophil phagocytosis and oxidative burst in blood from Metsupplemented cows indicated a better immune system status. However, the precise mechanisms for the priming effect are unknown. Human studies have reported that greater $\mathrm{Ca}^{2+}$ flux into PMNL increases markedly the oxidative burst intensity and the initiation of the oxidative burst (Bei et al., 1998). It is noteworthy that IL-6 increases intracellular stores of $\mathrm{Ca}^{2+}$, which is the known basis for PMNL activation and degranulation of oxidative burst oxidase-containing granules (Sitaraman et al., 2001). Therefore, considering the sustained greater concentration of IL- 6 together with the overall lower disease incidence in Met-supplemented cows (Zhou et al., 2016b), it can be speculated that Met supplementation enhanced phagocytosis and oxidative burst in PMNL at least in part by increasing intracellular $\mathrm{Ca}^{2+}$ stores, which sensitized or primed these cells for pathogen challenge.

Although the intensity of the oxidative burst in monocytes stimulated by $E$. coli was reported to be lower than in PMNL (Yan et al., 2012), monocytes also have the ability to phagocytose and carry out oxidative burst (Keogh et al., 2011). The fact that CHOL supplementation lead to greater monocyte oxidative burst indicates the existence of alternative mechanisms. Mechanisms related directly to metabolism of Met and CHOL or their metabolites by innate immune cells also could play a role. For instance, the respiratory burst in monocytes is accompanied by increased uptake of GSH (Seres et al., 2000). Studies with GSH reductasedeficient mice indicated they had an impaired oxidative burst and produced less ROM due to GSH depletion (Yan et al., 2012). In agreement with this, reduced neutrophil oxidative burst in humans was detected in response to chronic oxidative stress (Amer and Fibach, 2005). As precursors of GSH upstream in methionine cycle via transsulfuration pathway, it could be possible that supplemental Met and CHOL contributes to increased phagocytosis and oxidative burst upon challenge through increasing GSH availability to neutrophils and monocytes.

\section{CONCLUSIONS}

Overall, the changes observed in plasma PON, haptoglobin, and higher albumin revealed favorable alterations of liver function as well as inflammation status during lactation in Met-supplemented cows. Supplementation of Met resulted in better immune response in terms of greater phagocytosis and oxidative burst capabilities upon pathogen challenge. Biomarker analyses in blood, milk, and liver indicated that the effect of feeding Met on postpartal cow performance is likely due, in part, to a better immune and feed intake response. Although some previous studies have demonstrated beneficial effects of CHOL supplementation on performance, the contrasting responses detected between Met and CHOL supplementation on immunometabolic biomarkers in this study could be due, for example, to the fact that CHOL supplementation was insufficient for cows during the transition period. The requirements of CHOL and Met during the transition period, along with potential interactions at a mechanistic level, merit further study.

\section{ACKNOWLEDGMENTS}

The authors gratefully acknowledge Adisseo (Commentry, France) for partial financial support of this research. Zheng Zhou is a recipient of scholarship from China Scholarship Council (CSC, Beijing, China). We also thank Perdue AgriBusiness (Salisbury, MD) for the donation of ProVAAl AADvantage during the course of the experiment.

\section{REFERENCES}

Amer, J., and E. Fibach. 2005. Chronic oxidative stress reduces the respiratory burst response of neutrophils from beta-thalassaemia patients. Br. J. Haematol. 129:435-441.

Auboiron, S., D. Durand, J. C. Robert, M. J. Chapman, and D. Bauchart. 1995. Effects of dietary fat and L-methionine on the 
hepatic metabolism of very low density lipoproteins in the preruminant calf, Bos spp. Reprod. Nutr. Dev. 35:167-178.

Aviram, M., and M. Rosenblat. 2004. Paraoxonases 1, 2, and 3, oxidative stress, and macrophage foam cell formation during atherosclerosis development. Free Radic. Biol. Med. 37:1304-1316.

Bauman, P. F., T. K. Smith, and T. M. Bray. 1988. The effect of dietary protein and sulfur amino acids on hepatic glutathione concentration and glutathione-dependent enzyme activities in the rat. Can. J. Physiol. Pharmacol. 66:1048-1052.

Baumann, H., K. K. Morella, G. P. Jahreis, and S. Marinkovic. 1990. Distinct regulation of the interleukin-1 and interleukin-6 response elements of the rat haptoglobin gene in rat and human hepatoma cells. Mol. Cell. Biol. 10:5967-5976.

Bei, L., T. Hu, Z. M. Qian, and X. Shen. 1998. Extracellular Ca2+ regulates the respiratory burst of human neutrophils. Biochim. Biophys. Acta 1404:475-483.

Bell, A. W., W. S. Burhans, and T. R. Overton. 2000. Protein nutrition in late pregnancy, maternal protein reserves and lactation performance in dairy cows. Proc. Nutr. Soc. 59:119-126.

Benoit, S. L. A. 2009. Can choline spare methionine from catabolism in lactating mice and dairy cows? MS Thesis. Department of Animal and Avian Science, University of Maryland.

Bernabucci, U., B. Ronchi, L. Basirico, D. Pirazzi, F. Rueca, N Lacetera, and A. Nardone. 2004. Abundance of mRNA of apolipoprotein b100, apolipoprotein e, and microsomal triglyceride transfer protein in liver from periparturient dairy cows. J. Dairy Sci. 87:2881-2888.

Bernabucci, U., B. Ronchi, N. Lacetera, and A. Nardone. 2002. Markers of oxidative status in plasma and erythrocytes of transition dairy cows during hot season. J. Dairy Sci. 85:2173-2179.

Bernabucci, U., B. Ronchi, N. Lacetera, and A. Nardone. 2005. Influence of body condition score on relationships between metabolic status and oxidative stress in periparturient dairy cows. J. Dairy Sci. 88:2017-2026.

Bertoni, G., and E. Trevisi. 2013. Use of the liver activity index and other metabolic variables in the assessment of metabolic health in dairy herds. Vet. Clin. North Am. Food Anim. Pract. 29:413-431.

Bertoni, G., E. Trevisi, X. Han, and M. Bionaz. 2008. Effects of inflammatory conditions on liver activity in puerperium period and consequences for performance in dairy cows. J. Dairy Sci. 91:33003310.

Bertoni, G., E. Trevisi, and R. Lombardelli. 2009. Some new aspects of nutrition, health conditions and fertility of intensively reared dairy cows. Ital. J. Anim. Sci. 8:491-518.

Bionaz, M., E. Trevisi, L. Calamari, F. Librandi, A. Ferrari, and G. Bertoni. 2007. Plasma paraoxonase, health, inflammatory conditions, and liver function in transition dairy cows. J. Dairy Sci. 90:1740-1750.

Brosnan, J. T., and M. E. Brosnan. 2006. The sulfur-containing amino acids: An overview. J. Nutr. 136:1636S-1640S.

Burton, J. L., S. A. Madsen, L. C. Chang, P. S. Weber, K. R. Buckham, R. van Dorp, M. C. Hickey, and B. Earley. 2005. Gene expression signatures in neutrophils exposed to glucocorticoids: a new paradigm to help explain "neutrophil dysfunction" in parturient dairy cows. Vet. Immunol. Immunopathol. 105:197-219.

Ceciliani, F., J. J. Ceron, P. D. Eckersall, and H. Sauerwein. 2012. Acute phase proteins in ruminants. J. Proteomics 75:4207-4231.

Celi, P., A. Di Trana, and S. Claps. 2010. Effects of plane of nutrition on oxidative stress in goats during the peripartum period. Vet. J. 184:95-99.

Cho, E. S., N. Johnson, and B. C. Snider. 1984. Tissue glutathione as a cyst(e)ine reservoir during cystine depletion in growing rats. J. Nutr. 114:1853-1862.

Cohen, D. E. 2008. Balancing cholesterol synthesis and absorption in the gastrointestinal tract. J. Clin. Lipidol. 2:S1-S3.

Cooke, R. F., N. Silva Del Rio, D. Z. Caraviello, S. J. Bertics, M. H. Ramos, and R. R. Grummer. 2007. Supplemental choline for prevention and alleviation of fatty liver in dairy cattle. J. Dairy Sci. 90:2413-2418.
Corbin, K. D., and S. H. Zeisel. 2012. Choline metabolism provides novel insights into nonalcoholic fatty liver disease and its progression. Curr. Opin. Gastroenterol. 28:159-165.

Dann, H. M., D. E. Morin, G. A. Bollero, M. R. Murphy, and J. K. Drackley. 2005. Prepartum intake, postpartum induction of ketosis, and periparturient disorders affect the metabolic status of dairy cows. J. Dairy Sci. 88:3249-3264.

Drackley, J. K. 1999. ADSA Foundation Scholar Award. Biology of dairy cows during the transition period: The final frontier? J. Dairy Sci. 82:2259-2273.

Eckersall, P. D. 2000. Recent advances and future prospects for the use of acute phase proteins as markers of disease in animals. Rev. Med. Vet. (Toulouse) 151:577-584.

Franklin, C. C., D. S. Backos, I. Mohar, C. C. White, H. J. Forman, and T. J. Kavanagh. 2009. Structure, function, and post-translational regulation of the catalytic and modifier subunits of glutamate cysteine ligase. Mol. Aspects Med. 30:86-98.

Fukui, T., K. Yamauchi, M. Maruyama, T. Yasuda, M. Kohno, and Y. Abe. 2011. Significance of measuring oxidative stress in lifestyle-related diseases from the viewpoint of correlation between d-ROMs and BAP in Japanese subjects. Hypertens. Res. 34:1041-1045.

Girard, C. L., and J. J. Matte. 2005. Folic acid and vitamin B12 requirements of dairy cows: A concept to be revised. Livest. Prod. Sci. 98:123-133.

Goff, J. P., and R. L. Horst. 1997. Physiological changes at parturition and their relationship to metabolic disorders. J. Dairy Sci. $80: 1260-1268$

Goss, P. M., T. M. Bray, and L. E. Nagy. 1994. Regulation of hepatocyte glutathione by amino acid precursors and cAMP in proteinenergy malnourished rats. J. Nutr. 124:323-330.

Graulet, B., C. Richard, and J. C. Robert. 2005. Methionine availability in plasma of dairy cows supplemented with methionine hydroxy analog isopropyl ester. J. Dairy Sci. 88:3640-3649.

Grossi, P., G. Bertoni, F. P. Cappelli, and E. Trevisi. 2013. Effects of the precalving administration of omega-3 fatty acids alone or in combination with acetylsalicylic acid in periparturient dairy cows. J. Anim. Sci. 91:2657-2666

Guretzky, N. A., D. B. Carlson, J. E. Garrett, and J. K. Drackley. 2006. Lipid metabolite profiles and milk production for Holstein and Jersey cows fed rumen-protected choline during the periparturient period. J. Dairy Sci. 89:188-200.

Halsted, C. H. 2013. B-Vitamin dependent methionine metabolism and alcoholic liver disease. Clin. Chem. Lab. Med. 51:457-465.

Hartman, N. R., R. L. Cysyk, C. Bruneau-Wack, J.-P. Thénot, R. J. Parker, and J. M. Strong. 2002. Production of intracellular 35Sglutathione by rat and human hepatocytes for the quantification of xenobiotic reactive intermediates. Chem. Biol. Interact. 142:43-55.

Hirvonen, J., K. Eklund, A. M. Teppo, G. Huszenicza, M. Kulcsar, H. Saloniemi, and S. Pyorala. 1999. Acute phase response in dairy cows with experimentally induced Escherichia coli mastitis. Acta Vet. Scand. 40:35-46.

Hulbert, L. E., J. A. Carroll, N. C. Burdick, R. D. Randel, M. S. Brown, and M. A. Ballou. 2011. Innate immune responses of temperamental and calm cattle after transportation. Vet. Immunol. Immunopathol. 143:66-74.

Hunter, C. A., and S. A. Jones. 2015. IL-6 as a keystone cytokine in health and disease. Nat. Immunol. 16:448-457.

Jacometo, C. B., J. S. Osorio, M. Socha, M. N. Correa, F. PiccioliCappelli, E. Trevisi, and J. J. Loor. 2015. Maternal consumption of organic trace minerals alters calf systemic and neutrophil mRNA and microRNA indicators of inflammation and oxidative stress. J. Dairy Sci. 98:7717-7729.

Jahan, N., A. Minuti, and E. Trevisi. 2015. Assessment of immune response in periparturient dairy cows using ex vivo whole blood stimulation assay with lipopolysaccharides and carrageenan skin test. Vet. Immunol. Immunopathol. 165:119-126.

Jansen, E. H. J. M., P. K. Beekhof, J. W. J. M. Cremers, D. Viezeliene, V. Muzakova, and J. Skalicky. 2013. Short-term stability of biomarkers of oxidative stress and antioxidant status in hu- 
man serum. ISRN Biomarkers 2013:316528. http://dx.doi. org $/ 10.1155 / 2013 / 316528$.

Katoh, N., S. Oikawa, T. Oohashi, Y. Takahashi, and F. Itoh. 2002. Decreases of apolipoprotein B-100 and A-I concentrations and induction of haptoglobin and serum amyloid A in nonfed calves. J. Vet. Med. Sci. 64:51-55.

Kehrli, M. E. Jr., B. J. Nonnecke, and J. A. Roth. 1989. Alterations in bovine neutrophil function during the periparturient period. Am. J. Vet. Res. 50:207-214.

Keogh, M. J., T. Spoon, S. H. Ridgway, E. Jensen, W. Van Bonn, and T. A. Romano. 2011. Simultaneous measurement of phagocytosis and respiratory burst of leukocytes in whole blood from bottlenose dolphins (Tursiops truncatus) utilizing flow cytometry. Vet. Immunol. Immunopathol. 144:468-475.

Kokkonen, T., J. Taponen, T. Anttila, L. Syrjala-Qvist, C. Delavaud, Y. Chilliard, M. Tuori, and A. T. Tesfa. 2005. Effect of body fatness and glucogenic supplement on lipid and protein mobilization and plasma leptin in dairy cows. J. Dairy Sci. 88:1127-1141.

Lauder, S. N., E. Jones, K. Smart, A. Bloom, A. S. Williams, J. P. Hindley, B. Ondondo, P. R. Taylor, M. Clement, C. Fielding, A. J. Godkin, S. A. Jones, and A. M. Gallimore. 2013. Interleukin-6 limits influenza-induced inflammation and protects against fatal lung pathology. Eur. J. Immunol. 43:2613-2625.

Li, Z., and D. E. Vance. 2008. Phosphatidylcholine and choline homeostasis. J. Lipid Res. 49:1187-1194.

Loor, J. J., M. Bionaz, and J. K. Drackley. 2013. Systems physiology in dairy cattle: Nutritional genomics and beyond. Annu. Rev. Anim. Biosci. 1:365-392.

Osorio, J. S., P. Ji, J. K. Drackley, D. Luchini, and J. J. Loor. 2013 Supplemental Smartamine M or MetaSmart during the transition period benefits postpartal cow performance and blood neutrophil function. J. Dairy Sci. 96:6248-6263.

Osorio, J. S., E. Trevisi, P. Ji, J. K. Drackley, D. Luchini, G. Bertoni, and J. J. Loor. 2014. Biomarkers of inflammation, metabolism, and oxidative stress in blood, liver, and milk reveal a better immunometabolic status in peripartal cows supplemented with Smartamine M or MetaSmart. J. Dairy Sci. 97:7437-7450.

Pedersen, B. K., A. Steensberg, and P. Schjerling. 2001. Muscle-derived interleukin-6: possible biological effects. J. Physiol. 536:329-337.

Pinotti, L., A. Baldi, and V. Dell'Orto. 2002. Comparative mammalian choline metabolism with emphasis on the high-yielding dairy cow. Nutr. Res. Rev. 15:315-332.

Pires, J. A., C. Delavaud, Y. Faulconnier, D. Pomies, and Y. Chilliard. 2013. Effects of body condition score at calving on indicators of fat and protein mobilization of periparturient Holstein-Friesian cows. J. Dairy Sci. 96:6423-6439.

Rehman, J., P. J. Mills, S. M. Carter, J. Chou, J. Thomas, and A. S, Maisel. 1997. Dynamic exercise leads to an increase in circulating ICAM-1: Further evidence for adrenergic modulation of cell adhesion. Brain Behav. Immun. 11:343-351.

Romeu, M., R. Nogues, L. Marcas, V. Sánchez-Martos, M. Mulero, A. Martinez-Vea, J. Mallol, and M. Giralt. 2010. Evaluation of oxidative stress biomarkers inpatients with chronic renal failure: A case controlstudy. BMC Res. Notes 3:20-26.

Saharan, S., and P. K. Mandal. 2014. The emerging role of glutathione in Alzheimer's disease. J. Alzheimers Dis. 40:519-529.

Scheller, J., A. Chalaris, D. Schmidt-Arras, and S. Rose-John. 2011. The pro- and anti-inflammatory properties of the cytokine interleukin-6. Biochim. Biophys. Acta 1813:878-888.

Seres, T., R. G. Knickelbein, J. B. Warshaw, and R. B. Johnston Jr. 2000. The phagocytosis-associated respiratory burst in human monocytes is associated with increased uptake of glutathione. J. Immunol. 165:3333-3340.

Sharma, B. K., and R. A. Erdman. 1989. Effects of dietary and abomasally infused choline on milk production responses of lactating dairy cows. J. Nutr. 119:248-254.
Sheldon, I. M., D. E. Noakes, A. Rycroft, and H. Dobson. 2001. Acute phase protein responses to uterine bacterial contamination in cattle after calving. Vet. Rec. 148:172-175.

Sitaraman, S. V., D. Merlin, L. Wang, M. Wong, A. T. Gewirtz, M. Si-Tahar, and J. L. Madara. 2001. Neutrophil-epithelial crosstalk at the intestinal lumenal surface mediated by reciprocal secretion of adenosine and IL-6. J. Clin. Invest. 107:861-869.

Sordillo, L. M., G. A. Contreras, and S. L. Aitken. 2009. Metabolic factors affecting the inflammatory response of periparturient dairy cows. Anim. Health Res. Rev. 10:53-63.

Tabachnick, M. and H. Tarver. 1955. The conversion of methionineS35 to cystathionine-S35 and taurine-S35 in the rat. Arch. Biochem. Biophys. 56:115-122.

Trevisi, E., M. Amadori, A. M. Bakudila, and G. Bertoni. 2009. Metabolic changes in dairy cows induced by oral, low-dose interferonalpha treatment. J. Anim. Sci. 87:3020-3029.

Trevisi, E., M. Amadori, S. Cogrossi, E. Razzuoli, and G. Bertoni. 2012. Metabolic stress and inflammatory response in high-yielding, periparturient dairy cows. Res. Vet. Sci. 93:695-704.

Trevisi, E., N. Jahan, G. Bertoni, A. Ferrari, and A. Minuti. 2015. Pro-inflammatory cytokine profile in dairy cows: consequences for new lactation. Ital. J. Anim. Sci. 14:3862.

Turk, R., D. Juretic, D. Geres, N. Turk, B. Rekic, V. Simeon-Rudolf, and A. Svetina. 2004. Serum paraoxonase activity and lipid parameters in the early postpartum period of dairy cows. Res. Vet. Sci. $76: 57-61$.

Unanue, E. R. 1976. Secretory function of mononuclear phagocytes: a review. Am. J. Pathol. 83:396-418.

Vailati-Riboni, M., M. Kanwal, O. Bulgari, S. Meier, N. V. Priest, C. R. Burke, J. K. Kay, S. McDougall, M. D. Mitchell, C. G. Walker, M. Crookenden, A. Heiser, J. R. Roche, and J. J. Loor. 2016. Body condition score and plane of nutrition prepartum affect adipose tissue transcriptome regulators of metabolism and inflammation in grazing dairy cows during the transition period. J. Dairy Sci. 99:758-770.

van der Vusse, G. J. 2009. Albumin as fatty acid transporter. Drug Metab. Pharmacokinet. 24:300-307.

Vetrani, C., G. Costabile, L. Di Marino, and A. A. Rivellese. 2013. Nutrition and oxidative stress: a systematic review of human studies. Int. J. Food Sci. Nutr. 64:312-326.

Waterman, R., and L. H. Schultz. 1972. Methionine hydroxy analog treatment of bovine ketosis: Effects on circulating metabolites and interrelationships. J. Dairy Sci. 55:1513-1516.

Weinberg, J. M. 2006. Lipotoxicity. Kidney Int. 70:1560-1566.

Wong, E. R., and W. Thompson. 1972. Choline oxidation and labile methyl groups in normal and choline-deficient rat-liver. Biochim. Biophys. Acta 260:259-271.

Yan, J., X. Meng, L. M. Wancket, K. Lintner, L. D. Nelin, B. Chen, K. P. Francis, C. V. Smith, L. K. Rogers, and Y. Liu. 2012. Glutathione reductase facilitates host defense by sustaining phagocytic oxidative burst and promoting the development of neutrophil extracellular traps. J. Immunol. 188:2316-2327.

Zahra, L. C., T. F. Duffield, K. E. Leslie, T. R. Overton, D. Putnam, and S. J. LeBlanc. 2006. Effects of rumen-protected choline and monensin on milk production and metabolism of periparturient dairy cows. J. Dairy Sci. 89:4808-4818.

Zhou, Z., J. J. Loor, F. Piccioli-Cappelli, F. Librandi, G. E. Lobley, and E. Trevisi. 2016a. Circulating amino acids during the peripartal period in cows with different liver functionality index. J. Dairy Sci. 99:2257-2267.

Zhou, Z., M. Vailati-Riboni, E. Trevisi, J. K. Drackley, D. N. Luchini, and J. J. Loor. 2016b. Better postpartal performance in dairy cows supplemented with rumen-protected methionine than choline during the peripartal period. J. Dairy Sci. 99:8716-8732. http:// dx.doi.org/10.3168/jds.2015-10525. 